\title{
Integrated technological-economic modeling platform for energy and climate policy analysis
}

\author{
Patrícia Fortes* \\ CENSE, Departamento de Ciências e Engenharia do Ambiente, Faculdade de \\ Ciências e Tecnologia, Universidade Nova de Lisboa, Portugal \\ Alfredo Marvão Pereira \\ The College of William and Mary \\ Rui M. Pereira \\ The College of William and Mary \\ Júlia Seixas \\ CENSE, Departamento de Ciências e Engenharia do Ambiente, Faculdade de \\ Ciências e Tecnologia, Universidade Nova de Lisboa, Portugal.
}

College of William and Mary

Department of Economics

Working Paper Number 148

This Version: January 2014 
COLLEGE OF WILLIAM AND MARY

DEPARTMENT OF ECONOMICS

WORKING PAPER \# 148

January 2014

\title{
Integrated technological-economic modeling platform for energy and climate policy analysis
}

\begin{abstract}
Computable general equilibrium (CGE) and bottom-up models each have unique strengths and weakness in evaluating energy and climate policies. This paper describes the development of an integrated technological, economic modelling platform (HYBTEP), built through the soft-link between the bottomup TIMES and the CGE GEM-E3 models. HYBTEP combines cost minimizing energy technology choices with macroeconomic responses, which is essential for energy-climate policy assessment. HYBTEP advances on other hybrid tools by assuming 'full-form' models, integrating detailed and extensive technology data with disaggregated economic structure, and 'full-link', i.e., covering all economic sectors. Using Portugal as a case study, we examine three scenarios: i) the current energyclimate policy, ii) a $\mathrm{CO}_{2}$ tax, and iii) renewable energy subsidy, with the objective of assessing the advantages of HYBTEP vis-à-vis bottom-up approach. Results show that the economic framework in HYBTEP partially offsets the increase or decrease in energy costs from the policy scenarios, while TIMES sets a wide range of results, dependent of energy services-price elasticities. HYBTEP allows the computation of the economic impacts of policies while considers technological detail. Moreover, the hybrid platform increases the transparency of policy analysis by making explicit the mechanisms through which energy demand evolves, resulting in high confidence for decision-making.
\end{abstract}

Keywords: bottom-up, top-down, hybrid modeling, energy-climate policy

Patrícia Fortes

CENSE, Departamento de Ciências e Engenharia do Ambiente, Faculdade de Ciências e Tecnologia, Universidade Nova de Lisboa, Portugal p.fs@fct.unl.pt

\author{
Alfredo Marvão Pereira \\ Department of Economics, \\ The College of William and Mary, \\ Williamsburg, USA \\ PO Box 8795, Williamsburg, VA 23187 \\ ampere@wm.edu
}

Rui M. Pereira

Department of Economics, The College of William and Mary, Williamsburg, USA PO Box 8795, Williamsburg, VA 23187 rui.marvao.pereira@gmail.com

Júlia Seixas

CENSE, Departamento de Ciências e Engenharia do Ambiente, Faculdade de Ciências e Tecnologia, Universidade Nova de Lisboa, Portugal 


\section{Introduction}

Energy-economic-environmental models have been widely applied to support energy and climate policies, helping to explore and plan alternative energy futures and carbon mitigation strategies. Energy bottom-up (BU) and economic top-down (TD) models, are the two main modeling approaches used, differing essentially in the technological detail and endogenous market adjustments [1].

$\mathrm{BU}$ models describe the energy system with great technological detail, usually defining the least cost combination of technologies to meet given energy services demand. Because BU models ignore that emergent technologies have greater financial risk, or may not be perfect substitutes to consumers, they do not provide a realistic microeconomic framework [2]. Moreover, they neglect interactions among the energy system and the rest of the economy. To accommodate responses to prices change, these models allow for energy service demand adjustments through energy service

price-elasticities. Some authors (e.g., $[3,4]$ ) argue that this response captures part of the feedback effects between the energy system and the economy. Good estimates of energy services price-elasticities are rare, however, as the econometric literature focuses mostly on energy demand [5].

Conventional TD models, namely computable general equilibrium (CGE), adopt an economic perspective, incorporating markets interaction and its response to policy measures. The energy sector is represented by aggregated production functions, capturing substitution possibilities between input factors and energy forms through substitution elasticities [1]. These are usually estimated from historical data, with no guarantee that they will remain valid in the future [6]. CGE models enjoy widespread use in evaluating market based energy and environmental policy instruments, such as, 
energy or carbon taxes. Yet, due to the lack of detailed technology information, they have proven ineffective in assessing technology policies, while violations of energy and matter conservation principles may occur [7].

Decision makers need clear and consistent information concerning the impact of energy and climate policies in the economy, as well as the cost-effective technology portfolio to achieve their goals. Historical use of CGE and BU models has not adequately address these various policy dimensions. Hybrid models, that combine the two approaches, have been developed, with the objective of providing an integrated modeling framework: technologically explicit, with strong microeconomic foundations and macroeconomic closure [8].

Hybrid models can be classified according to their different approaches to integration. One method is a 'soft-link' between two independent TD and BU models, exchanging data and solving them iteratively until the two models converge (e.g., [9,10]). This approach has the advantage of being a transparent process and allows the use of complete models, as its computational complexity and running times are generally manageable [11]. However, due to the heterogeneity of the models, it may be difficult to achieve consistency and convergence [7]. Although some soft-linking processes have been implemented, they are mostly done through a single sector alone, e.g., transport [12], residential [13], electricity [11], thereby lacking in a full macroeconomic feedback over the range of technological choices of the entire energy system.

Another approach is linking one model to a reduced form of the other. The most common development is to couple a simple macroeconomic sector, producing a single non-energy good, to a BU model (e.g., [14-18]). Although this method includes energy- 
economy interactions, its high aggregation limits its usefulness in assessing sector specific effects.

A third approach combines BU and TD models in a Mixed Complementarity Problem (MCP) format (e.g., [1,19-22]), introducing BU technological detail (commonly discrete electricity generation technologies) into a CGE framework. Its complexity and dimensionality, however, restricts the introduction of an extensive set of technologies, limiting the analysis of technology-oriented policies. Böhringer and Rutherford [7] have further outlined a method to decompose and solve iteratively MCP model, overcoming dimensionality issues $([23,24]$ applied this method using just electricity generation BU models).

Despite the extensive literature on hybrid models, there are few quantitative examples employing a 'full-link' (i.e., not focusing on only one sector) and 'full-form' BU and TD approaches (i.e., extensive technology data and disaggregated economic structure). This paper proposes a 'full-link' and a 'full-form' hybrid model, supported by an integrated methodology to soft-link the extensively applied BU TIMES model, developed by Energy Technology Systems Analysis Program (ETSAP) of the International Energy Agency $^{1}$ (IEA), with the CGE GEM-E3 model, used by several Directorates General of the European Commission². The hybrid platform, hereafter named HYBTEP (Hybrid Technological Economic Platform), applied to the Portuguese case, is defined by the

\footnotetext{
${ }^{1}$ See http://www.iea-etsap.org/web/Applications.asp for a list of TIMES applications and respective publications.

${ }^{2}$ See http://ipts.jrc.ec.europa.eu/activities/energy-and-transport/gem-e3/publications.cfm for a list of GEME3 applications and respective publications.
} 
soft-link between single country versions of the two models: TIMES_PT and GEME3_PT.

This paper presents a detailed description of the HYBTEP modeling framework and its application in three policy scenarios. The objective is to provide insights on the advantages of HYBTEP in assessing the impact of climate and energy policies on the energy system and the economy, and in defining mitigation strategies, when compared with conventional BU models. Thus, HYBTEP results are compared with TIMES outcomes considering different values for energy service-price elasticities, evaluating the performance of the modeling tools under each policy scenario.

The remainder of the paper is organized as follows: Section 2 describes TIMES and GEM-E3, and the linking methodology to build HYBTEP. Section 3 presents the calibration procedure between the models and outlines the assumptions under each policy scenario. Section 4 investigates the impact of the policy scenarios on the energy system, greenhouse gas (GHG) emissions and the economy, allowing for a comparison between HYBTEP and TIMES outcomes. Section 5 concludes and evaluates the strengths and weakness of the hybrid approach in the assessment of energy and climate mitigation policies.

\section{Methodology}

This section presents a characterization of the two models connected in HYBTEP modeling framework, as well as a description of the soft-link methodology. 


\subsection{TIMES model}

TIMES (The Integrated MARKAL-EFOM system) is an inter-temporal linear optimization energy model generator. In its partial equilibrium formulation, the objective of TIMES is to minimize total energy system cost to satisfy energy services demand, i.e., maximization of the total net surplus, subject to technological, physical and policy constraints. The model computes the energy demand/supply equilibrium, by making simultaneous decisions about technology investment and operating costs, primary energy supply and energy trade [25], in an environment in which all agents have perfect foresight.

TIMES_PT characterizes the entire chain of the Portuguese energy system from 2005 to 2050, including energy imports and production (e.g., oil and bio refineries), transformation, (e.g., power and heat production), distribution, exports and end-use consumption, in industry, residential, services, agriculture and transport sectors and their respective sub-sectors. The model contains three energy economy entities, which define the Reference Energy System [25]: i) Technologies, corresponding to processes that transform energy commodities into other energy commodities (e.g., electricity generation technologies) or fulfill energy services demand. The TIMES_PT technological database has more than two thousands existing and future, supply and demand, energy technologies, with detailed information such as efficiency, capacity factor, availability, technical lifetime, investment, operation and maintenance costs and emission factors. ii) Commodities, comprising energy carriers, energy services, materials and emissions. A commodity is generally produced by some technologies (output) and consumed by others (input). iii) Commodities flows, which link processes and commodities. 
TIMES_PT is driven by energy service demands, which are external to the model or are dependent of its endogenous energy costs through energy service-price elasticities. In its elastic demand version (hereafter called TIMES-ED), the model can increase or reduce energy service demand as a function of their market price in an alternative scenario (e.g., a policy scenario) as in Eq. (1).

$$
D_{j, t}=D 0_{j, t} \cdot\left(P_{j, t} / P 0_{j, t}\right)^{e l a s_{j}}
$$

Where,

$\mathrm{D}_{\mathrm{j}, \mathrm{t}}$ is the demand for energy service $j$, at time period $t$, in a counterfactual scenario; $\mathrm{D} 0_{\mathrm{j}, \mathrm{t}}$ is the demand for energy service $j$, at time period $t$, in the base scenario;

$\mathrm{P}_{\mathrm{j}, \mathrm{t}}$ is the marginal price of energy service demand $j$, determined by TIMES, at time period $t$, in a counterfactual scenario,;

$\mathrm{PO}_{\mathrm{j}, \mathrm{t}}$ is the marginal price of energy service demand $j$, determined by TIMES, at time period $t$, in the base scenario,;

elas $_{\mathrm{j}}$ is the (negative) price elasticity of the energy service demand $j$.

\subsection{GEM-E3 model}

GEM-E3 (General Equilibrium Model for Economy, Energy, Environment) is a multiregional, multi-sector, recursive dynamic CGE model, describing the interactions between economy, energy and environment [26]. The model computes the equilibrium price of goods, services, labor and capital that simultaneously clear all markets and optimize the behavior of economic agents.

GEM-E3_PT corresponds to a single country version of the model, covering the Portuguese economy. It is based on data for the benchmark year 2005, combining the Portuguese economic Social Accounting Matrix (SAM), from national account statistics [27] and input-output tables [28], with price and physical energy data and GHG 
emissions $\left(\mathrm{CO}_{2}, \mathrm{CH}_{4}\right.$ and $\left.\mathrm{N}_{2} \mathrm{O}\right)$, from national energy balance [29] and emissions inventories [30], respectively.

In GEM-E3_PT, firms maximize profits producing output according to a four-level nested constant substitution elasticity (CES) production function, which combines primary factors (capital and labor) with intermediate consumption of materials, services and energy (coal, oil, natural gas and electricity) (Figure 1). The model includes eighteen production sectors ranging from agriculture, energy industries (including oil refinery and power and heat production), iron \& steel industry, land transport, services of credit and insurances, among other.

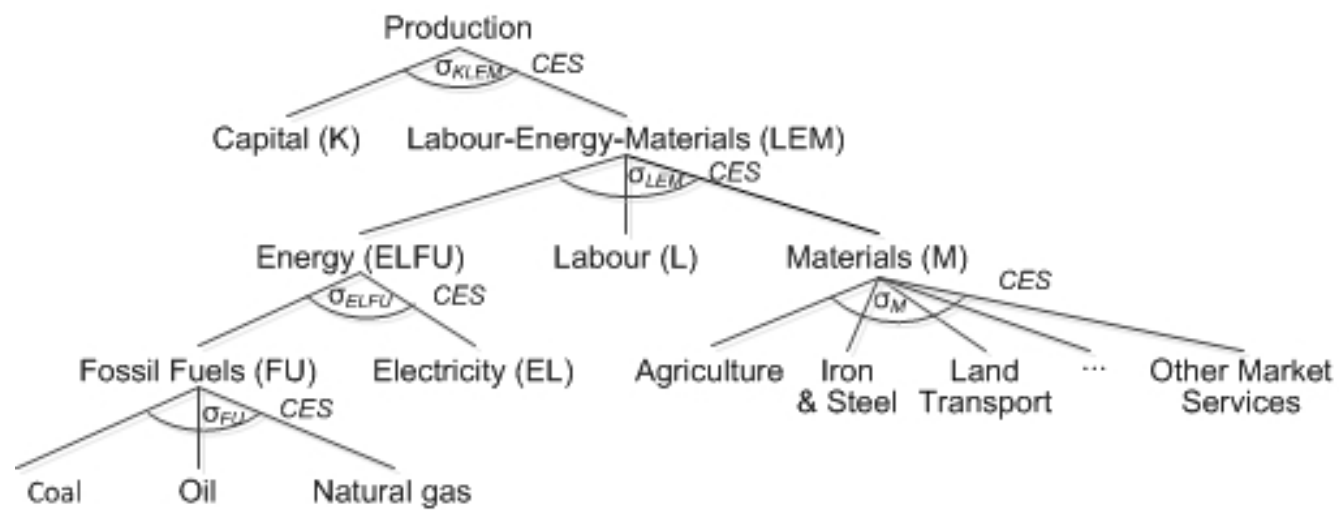

Figure 1 - Nesting constant substitution elasticity production structure of standard GEM-E3_PT

Households maximize their inter-temporal utility, in an extended linear expenditure system (LES), choosing between present and future consumption of goods/services, leisure and savings, subject to a budget constraint. Their consumption is thereafter allocated between eleven non-durable consumption categories, such as, food, clothing, health services, culture, fuels and power and two durable goods: residential heating systems/electric appliances and private transport equipment, which are associated with productive sectors through fixed coefficients. 
Bilateral trade between Portugal and the rest of the World follows an Armington specification, thus total demand is allocated between produced and imported goods, under the hypothesis that these are imperfect substitutes. GEM-E3_PT Armington elasticities are derived from the European GEM-E3 model [26].

Government behavior is set exogenously based on economic projections. Its income is generated through the collection of taxes, as, social security, import duties, value added and environment taxes, which are spend in public consumption, investment and transfer to other economic agents. In the current analysis we impose a revenue-neutrality, in the sense that government's deficit/surplus is fixed as percentage of gross domestic product (GDP), and additional revenues are recycled to economy to reduce endogenously employers' social security tax.

\subsection{HYBTEP soft-link methodology}

HYBTEP corresponds to a modeling platform built through an iterative process to link the two abovementioned models. Inspired by the work of [10], we set an approach whereby, TIMES_PT provides the configuration and the evolution of energy costs for the Portuguese energy system, which is assumed by GEM-E3_PT. The CGE model in its turn, defines the configuration of the national economic structure, driving the energy services demand that feeds TIMES_PT. The two models are solved independently and in succession, reconciling the equilibrium of energy sector profile and energy system costs. 


\section{Defining coherence between the two models}

The integration of the two modeling frameworks requires the establishment of a coherent data structure across the modeling tools. This primarily manifested itself through the correspondence between the different activity sectors and energy commodities disaggregation across the two models (Table 1). The corresponding sectors and commodities (i.e., HYBTEP disaggregation) were further used as interaction indexes in the soft-linking methodology. 
Table 1 - Correspondence between GEM-E3_PT and TIMES_PT activity sectors and energy commodities in HYBTEP

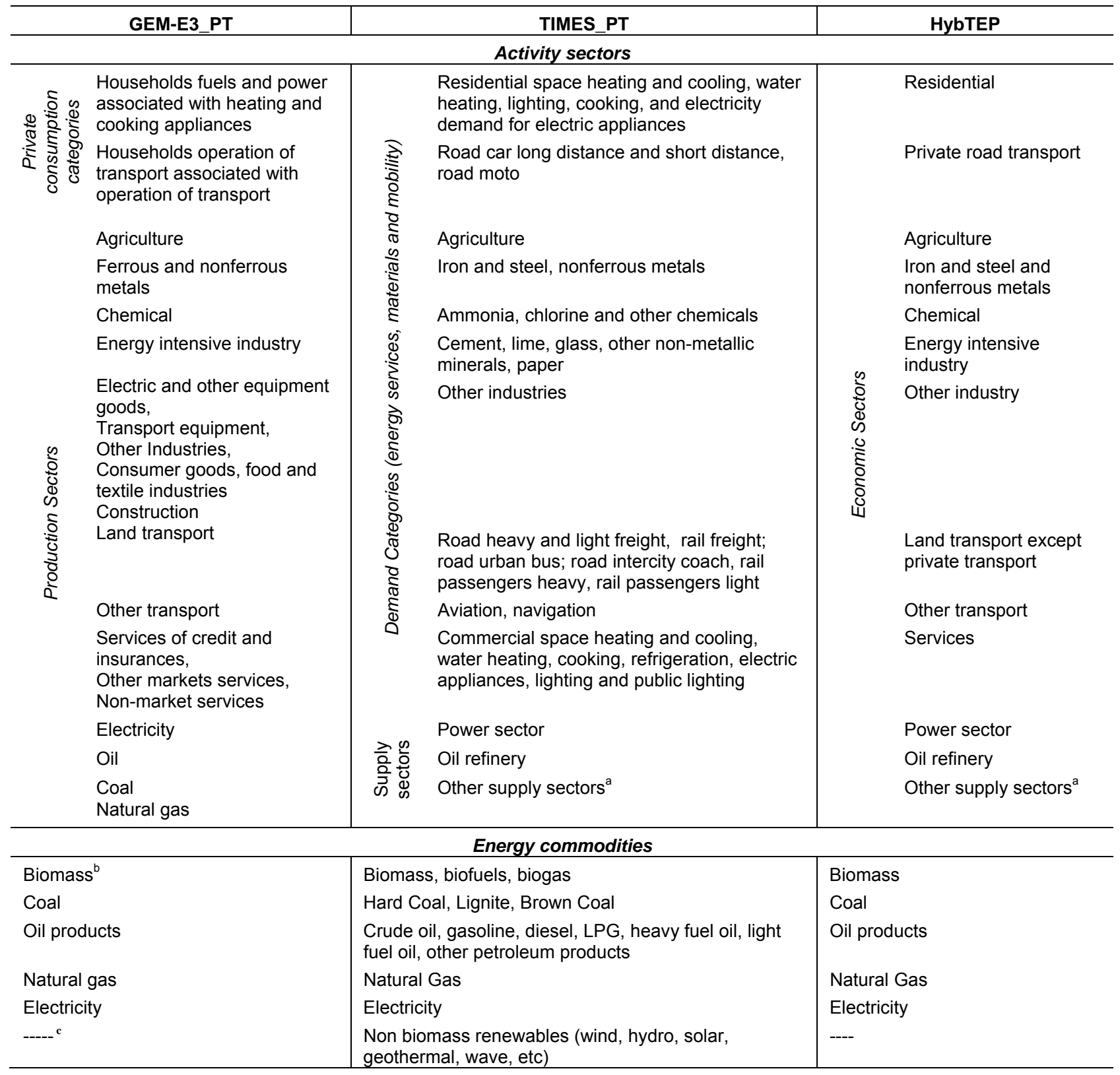

${ }^{a}$ Without significance in Portugal due to the absence of coal mining and natural gas extraction.

${ }^{b}$ Although the standard version of GEM-E3_PT does no assume biomass as an energy commodity, in HYBTEP we added biomass produced by Agriculture sector as a new energy commodity, allocating its overall demand to the intermediate consumption of different sectors.

${ }^{c}$ It should be underline that due to its nature (a standard CGE model sustained by national accounts), GEM-E3_PT does not represent explicitly renewable energy sources.

A crucial step to achieve consistency among the models is associated with the definition of common scenario assumptions, namely fossil fuel import prices, interest rates, energy constraints and policy assumptions. In the present analysis, we defined the following 
equal conditions for both models and across scenarios: i) an interest rate of $4 \%$; ii) fossil fuel import prices according to 4D scenario of the World Energy Technology Perspectives from IEA ([31]) with prices in 2050 reaching US $\$ 2010118 /$ barrel for crude oil, US\$201012/MBTU for natural gas, and US\$2010109/ton for coal; iii) restrictions on Iberian electricity trade, which is set to zero after 2015, preventing GHG leakage and inconsistence between the models results.

\section{Developing a new energy module in GEM-E3_PT}

To allow GEM-E3_PT to replicate the energy system profile defined by TIMES_PT outputs, the model's CES production technology for the top level energy aggregate (ELFU), was replaced by a Leontieff function, setting the CES elasticities to zero and defining exogenously total energy consumption and the shares for energy consumption by carrier and sector. The model structure above this nest was preserved, as depicted in Figure 2. As a result of these changes, the demand functions for the electricity, fuel aggregate and fuel consumption (Eq. (2)-(5)) of standard GEM-E3_PT were replaced by Eq. (6) and Eq. (7) associated with a new linking energy module.

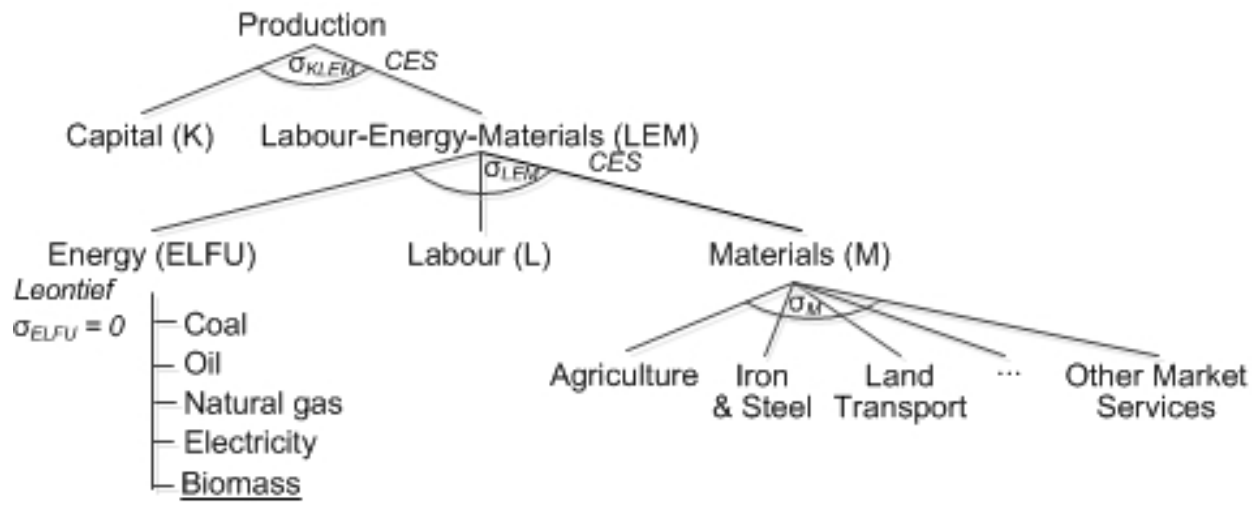

Figure 2 - Nesting constant substitution elasticity production structure of modified GEM-E3_PT in HYTEP version 
Standard GEM-E3_PT:

$$
\begin{aligned}
& E L F U_{S, t}=L E M_{S, t} \cdot \delta_{E L F U_{S}} \cdot\left(P L E M_{S, t} / P E L F U_{S, t}\right)^{\sigma_{L E M_{S, t}}} \\
& E L_{S, t}=E L F U_{S, t} \cdot \delta_{E L_{S}} \cdot\left(P E L F U_{S, t} / P E L_{S, t}\right)^{\sigma_{E L F U_{S, t}}} \cdot e^{t g e_{e l, S, t} \cdot\left(\sigma_{E L F U_{S, t}}-1\right)} \\
& F U_{S, t}=E L F U_{S, t} \cdot \delta_{F U_{S}} \cdot\left(P E L F U_{S, t} / P F U_{S, t}\right)^{\sigma_{E L F U_{S, t}}} \\
& F F_{f, S, t}=F U_{f, S, t} \cdot \delta_{F F_{, S}} \cdot\left(P F U_{S, t} / P E_{f, S, t}\right)^{\sigma_{F U}} \exp ^{t g e_{f, S, t} \cdot\left(\sigma_{F U_{S, t}}-1\right)} \forall f=\text { coal, oil, gas }
\end{aligned}
$$

Where,

$E L F U_{S, t}$ is the energy aggregated consumption per productive sector $S$ and time period $t$; $E L_{S, t}$ is the electricity consumption per productive sector $S$ and time period $t$; $F U_{S, t}$ is the fuel aggregate consumption per productive sector $S$ and time period $t$; $F F_{f, S, t}$ is the fuel consumption per fuel carrier $f$, productive sector $S$ and time period $t$; $L E M_{S, t}$ denotes the labour-energy-materials aggregate per productive sector $S$ and time period $t$; $\delta_{E L F U_{S}}, \delta_{E L_{S}}, \delta_{F U_{S}}$ and $\delta_{F F S}$ represent the scale factors for $E L F U, E L, F U$ and $F F$, respectively, derived from the base year 2005;

$P L E M_{S, t}, P E L F U_{S, t}, P E L_{S, t}$ and $P E_{f, S, t}$ represent the price of $L E M, E L F U, E L$ and energy (per fuel type $f$ ), respectively, per sector $S$ and time period $t$;

$\sigma_{L E M_{S, t}}, \sigma_{E L F U_{S, t}}, \sigma_{F U_{S, t}}$ are the substitutions elasticities between Labour, Energy, Materials productive factors, between Electricity and Fuels and between Fuel carriers, respectively; $\operatorname{tg}_{e l, S, t}$ and $\operatorname{tg}_{f, S, t}$ are the technical progress of electricity $(e /)$ and technical progress for each fuel type $(f)$, respectively, per sector $S$ and time period $t$.

HYBTEP:

$$
\begin{aligned}
& E L F U_{S, t}=\sum_{e} \frac{E C_{e, S, t}}{\operatorname{CONVERS}_{e} \cdot\left(1-N E U_{e, S}\right)} \\
& E S_{e, S, t}=\alpha_{e, S, t} \cdot E L F U_{S, t}
\end{aligned}
$$

Where,

$E C_{e, S, t}$ is the physical energy consumption from TIMES_PT results per energy commodity $e$ (electricity, biomass, coal, oil and natural gas), sector $S$ and time period $t$;

$\mathrm{CONVERS}_{e}$ represents a conversion parameter that "transform" the physical units of energy consumption from TIMES_PT in monetary units for GEM-E3_PT. CONVERS $S_{e}$ is calibrated in the 
base year (2005) trough IEA energy prices and taxes statistics [32], energy balance [29] and national accounts [27];

$N E U_{e, S}$ represents the share of non-energy uses in energy commodity $e$ and sector $S$. The parameter refers for example to the energy products consumed as raw materials in the chemical, industry. $N E U_{e, S}$ is calibrated in base year through national energy balance and national accounts and kept constant;

$E S_{e, S, t}$ is the energy consumption in monetary units per energy commodity $e$, sector $S$ and time period $t . E S_{e, S, t}$ symbolizes $E L_{S, t}, F U_{S, t}$ and $F F_{S, t}$ when $e$ is referred to electricity, the sum of fossil fuels and each fossil fuel, respectively;

$\alpha_{e, S, t}$ is the share of each energy commodity $e$ in total energy consumption, per sector $S$ and time $t$ (i.e., is the amount of each energy commodity in monetary units per $E L F U_{S, t}$ ). It must be the case that (Eq. (8)):

$$
\sum_{e} \alpha_{e, S, t}=1
$$

These changes further implied alterations to the definition of the price of the energy aggregate, as following (Eq. (9) and Eq. (10)):

\section{Standard GEM-E3_PT:}

$$
P E L F U_{S, t}=\left[\delta_{E L_{S}} \cdot\left(P E L_{S, t} \cdot e^{\left(-t g e_{E L C, S, t}\right)}\right)^{\left(1-\sigma_{E L F U_{S, t}}\right)}+\delta_{F U_{S}} \cdot P F U_{S, t}\left(1-\sigma_{E L F U_{S, t}}\right)\right]^{\frac{1}{1-\sigma_{E L F U}}}
$$

HybTEP:

$$
P E L F U_{S, t}=P E L F U_{S, t-1} \cdot\left(1+\Delta \frac{T C O S T_{S, t}}{E L F U_{S, t}}\right)
$$

Where,

$\Delta \frac{T \operatorname{COST}_{S, t}}{E L F U_{S, t}}$ represents the annual growth rate of the total system costs from TIMES_PT outcomes for each energy aggregate $\left(E L F U_{S, t}\right)$ per sector $S$, from time period $t-1$ to $t$. $T C O S T_{S, t}$ includes technology investment, operation and maintenance costs, fuel costs, plus energy and/or environmental taxes, minus subsidies. 
Regarding households, the GEM-E3_PT specification for private consumption activities was preserved with the exception of expenditures on Fuels and Power and Operation of Transport which were defined exogenously according to TIMES_PT model outcomes. The physical units for energy demand were converted in monetary units as in Eq. (6) and Eq. (7). Moreover, the fixed shares of energy consumption in the total expenditure categories were altered to reflect substitution among energy carriers in the demand for Fuels and Power and Operation of Transport. The energy price structure in households was not changed as it is determined as a weighted average of the price of output from each energy productive sector (e.g. electricity price from power generation sector) contributing to the production of a particular household commodity demand group.

In the standard GEM-E3_PT, energy efficiency improvements are considered through an exogenous energy productivity variable. Usually this value is based on historical data or future political goals (e.g. energy efficiency standards). Within HYBTEP integrated modeling platform, GEM-E3_PT energy efficiency is based on TIMES_PT outcomes as shown is Eq. (11) and Eq. (12):

$$
\begin{aligned}
e f f_{S, t} & =P R O D_{S, t} / \sum_{e} E C_{e, S, t} \\
\theta_{S, t} & =e f f_{S, t} / e f f_{S, 2005}
\end{aligned}
$$

Where,

ef $f_{e, S, t}$ denotes the energy efficiency per energy commodity $e$, sector $S$ and period $t$;

PROD $D_{S, t}$ represents TIMES_PT production values for the case of electricity and some industrial processes (cement, paper, glass, iron \& steel, lime), mobility for transports and energy services demand for residential, services, agriculture and other industrial sectors (e.g. chemical, nonmetallic mineral products, other industry); 
$\theta_{S, t}=$ energy efficiency improvement index per sector $S$ and period $t$.

\section{Defining the iteration procedure and convergence between the two models}

Figure 3 presents the schematic view of HYBTEP platform, which comprises the following iteration steps:

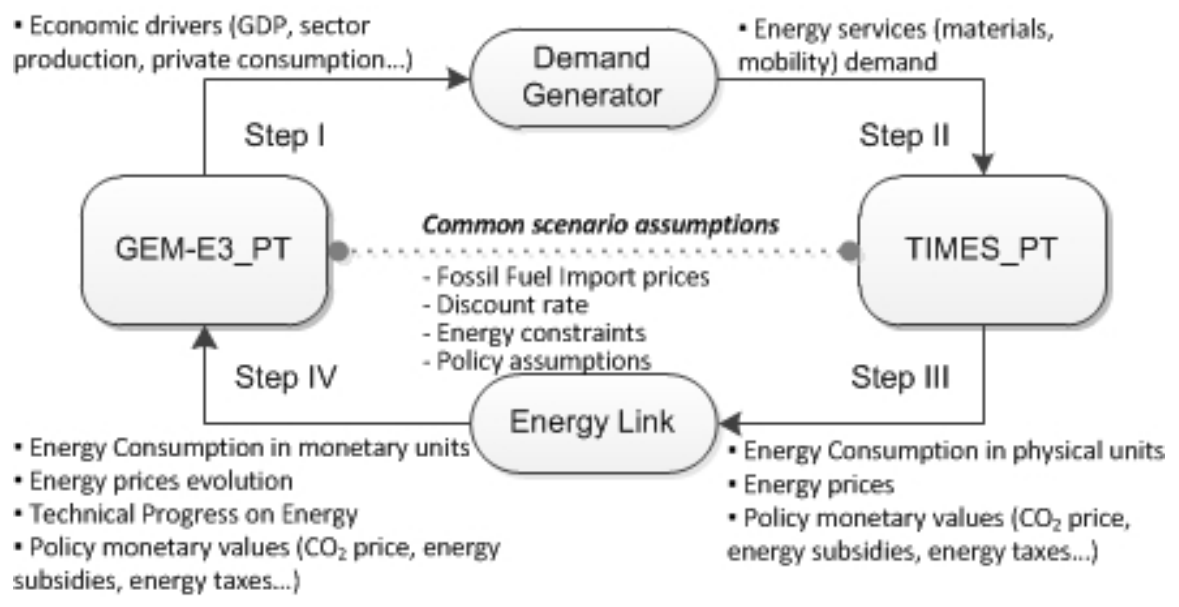

Figure 3 - Schematic view of HYBTEP soft-link framework

Step I: GEM-E3_PT is run assuming some exogenous input variables, namely, world energy import prices, energy constraints (e.g. no electricity trade), active population growth, technical progress ${ }^{3}$ (capital, labor and materials) and expectations on future sector-specific growth. The two latter exogenous variables are calibrated so the model could produce a reference scenario consistent with a predefined economic projection. The model outputs, including GDP, sector production and private consumption are used to produce energy services, materials and mobility demand according to Eq. (13) and Eq. (14) of demand generator module:

\footnotetext{
${ }^{3}$ In the first iteration, the technical progress of energy was set to zero. In the subsequent iterations and as explained before this parameter was determined based on TIMES_PT results.
} 
$D_{j, t}=D_{j, t-1} \cdot\left(1+D R G R_{j, t} \times E L A S I_{j}\right) \cdot\left(1-A E E I_{j}\right)$

$D_{j, t}=K M_{j, t-1} *\left(\left(1+R S H_{t} \times E L A S I_{j}\right) \cdot P o p_{t} \forall j=p . k m\right.$ for cars short distance, long

distance and motorcycles

Where,

$D_{j, t}$ is the demand for each energy service, material or mobility $j$ (see Table 1 for an overview of TIMES_PT demand categories), in time period $t$. For the base year (2005), $D_{j, 2005}$ was developed considering the historic national materials and energy consumption and the corresponded technological profile and its characteristics, namely installed capacity, efficiency, availability, among other factors;

$D R G R_{j, t}$ is the annual growth of population and the economic drivers from GEM-E3_PT (i.e., GDP, private consumption, sector production) associated with each energy service, material and mobility demand $j$;

$E L A S j$ is the income elasticity per energy service, material and mobility demand $j$;

AEEIj is autonomous energy efficiency improvement factor in industrial sectors;

$K M_{j, t-1}$ is the average $\mathrm{km}$ travelled by habitant for the demand categories cars short distance, cars long distance and motorcycles for period $t-1$;

$\mathrm{RSH}_{t}$ is the annual growth of private consumption per household in period $t$;

$\mathrm{Pop}_{t}$ is the resident population in period $t$.

For the residential sector, demand is generated through a more complex formula, which depends on the age and characteristics of dwellings (new or existing, single house situated in rural or urban area or multi apartment), the number of persons per house, among other parameters as explain in [33].

Step II: The energy service and materials demand projected by the Demand Generator module are entered into TIMES_PT, which defines the energy system configuration, determining, among other important quantities, the energy consumption (quantities per sector per energy source), the corresponding GHG emissions and system costs which includes investment, operation and maintenance, fuel costs, subsidies and/or taxes. 
TIMES_PT is run assuming the same interest rate, world energy prices and energy constraints considered in GEM-E3_PT. Energy taxation in the Portuguese economy, which includes excise duties on energy, is also included in TIMES_PT, and is assumed to remain constant through 2050.

Step III: TIMES_PT physical energy consumption and system costs are 'translated' in GEM-E3_PT monetary units, technical progress on energy and energy prices through an Energy Link Module, comprising Eq. (6), Eq.(7), and Eq. (10)-(12). When a market policy instrument is being considered in TIMES_PT, e.g., an energy tax or a feed-in tariff, the respective economic value is also included in GEM-E3_PT associated with the respective payer and payee sectors. This way the CGE model assumes the transfers between the economic agents and computes the impact of those on economy. GEME3_PT emission factors per energy carrier and sector are also adjusted to reflect TIMES_PT emissions. This change is of special relevance when the BU model selects carbon capture and storage technologies.

Step IV: GEM-E3_PT is run, sustain by its new algebraic formulation and STEP III outputs.

Modifications in the energy profile and prices can have impact on the economic projections structure described by GEM-E3_PT and, consequently, on TIMES_PT demand categories. Thus, to reflect the macroeconomic feedback of the changes in the energy system, the four steps described above are repeated until the two models converge to a satisfactory level, which is defined with respect to the following metric (Eq. (15)), close to [10] convergence criteria: 


$$
\operatorname{Max} C_{j}=\frac{\sqrt{\sum_{t=2005}^{2050}\left(D_{j, t, i}-D_{j, t, i-1}\right)^{2}}}{\sqrt{\sum_{t=2005}^{2050} D_{j, t, i}^{2}}}<\beta
$$

Where:

$C_{j}$ is the convergence function per demand category $j$;

$D_{j, t, i}$ indicates the energy services demand of category $j$, at time period $t$, in iteration $i$.

$\beta$ represents the iteration stopping threshold, reflecting the fact that with minimal energy service demand differences, the energy sector profile and energy system costs of iteration $i$ and $i-1$ are defined to be very small and consequently the economic drivers from GEM-E3_PT, achieving convergence across the two models results.

As observed by [34], in some cases, due to the stepped supply curves stemming from discrete choices consistent with linear programming models like TIMES_PT, small changes in energy services demand can induce considerable changes in the energy prices, prompting, in turn, fluctuations in energy services demand between iterations. Competing technologies have different costs, and deployment limits, associated with maximum capacity or primary energy potentials. Thus, when a technology achieves its maximum availability, a new technology is installed, which may have significant higher costs. When energy service demand is not convergent we considered an approach close to $[10,34]$, assuming that the optimal demand level lies between the previous iteration values ${ }^{4}$

\footnotetext{
${ }^{4}$ In the present paper this situation only happen with the RES policy scenario (section 3.2) regarding chemical energy services demand, representing currently just $1 \%$ of the Portuguese GDP [27] and less than $3.5 \%$ of the national final energy consumption [29].
} 


\section{Scenarios Simulation}

The main goal of this paper is to evaluate whether HYBTEP represents a more suitable tool than a conventional bottom-up model, to assess the impact of energy and climate policies on the energy system and GHG emissions. We design three policy scenarios, reflecting current climate and energy regulation and additional policy assumptions, to evaluate the performance of both tools. The GEM-E3_PT and TIMES_PT were harmonized and calibrated within a Calibration scenario, used as starting point for the subsequent counterfactual policy simulations. This section outlines the assumptions for each scenario.

\subsection{Calibration scenario}

To harmonize the two modeling tools and test the iteration and convergence procedure, we developed a Calibration scenario (CALIB), reflecting the evolution of the Portuguese economy and energy system in the absence of any energy and climate policy constraints. It should be noted that this scenario does not represent a business-as-usual scenario, as TIMES_PT was left 'free' to optimize the energy system.

The evolution of the energy system is driven by a large number of factors, including economic activity and demography. The socio-economic scenario considered for CALIB was generated within the national project $\mathrm{HybCO}^{5}$ [35]. It comprises a decline in population (-0.3\% p.a. from 2015 to 2050$)$, and a moderate evolution of the economy after the current economic crises (GDP annual growth of $0.1 \%$ from 2010 to 2020 and

\footnotetext{
${ }^{5}$ HybCO2 Project: "Hybrid approaches to assess the economic, environmental and technological impact of long term carbon reduction scenarios - the Portuguese case-study" (http://hybco2.cense.fct.unl.pt/)
} 
$1.5 \%$ from 2020 to 2050), consistent with the 2012 European (EU) Ageing Report projections [36].

After calibrating GEM-E3_PT exogenous variables in line with the above mentioned economic assumptions, the two models were run in HYBTEP iterative process, achieving consistency after 3 iterations (Figure 4). The demand for energy services resulting from the calibration process was used for the policy scenario simulations because it represents equilibrium between TIMES_PT energy system and GEM-E3_PT economic structure.

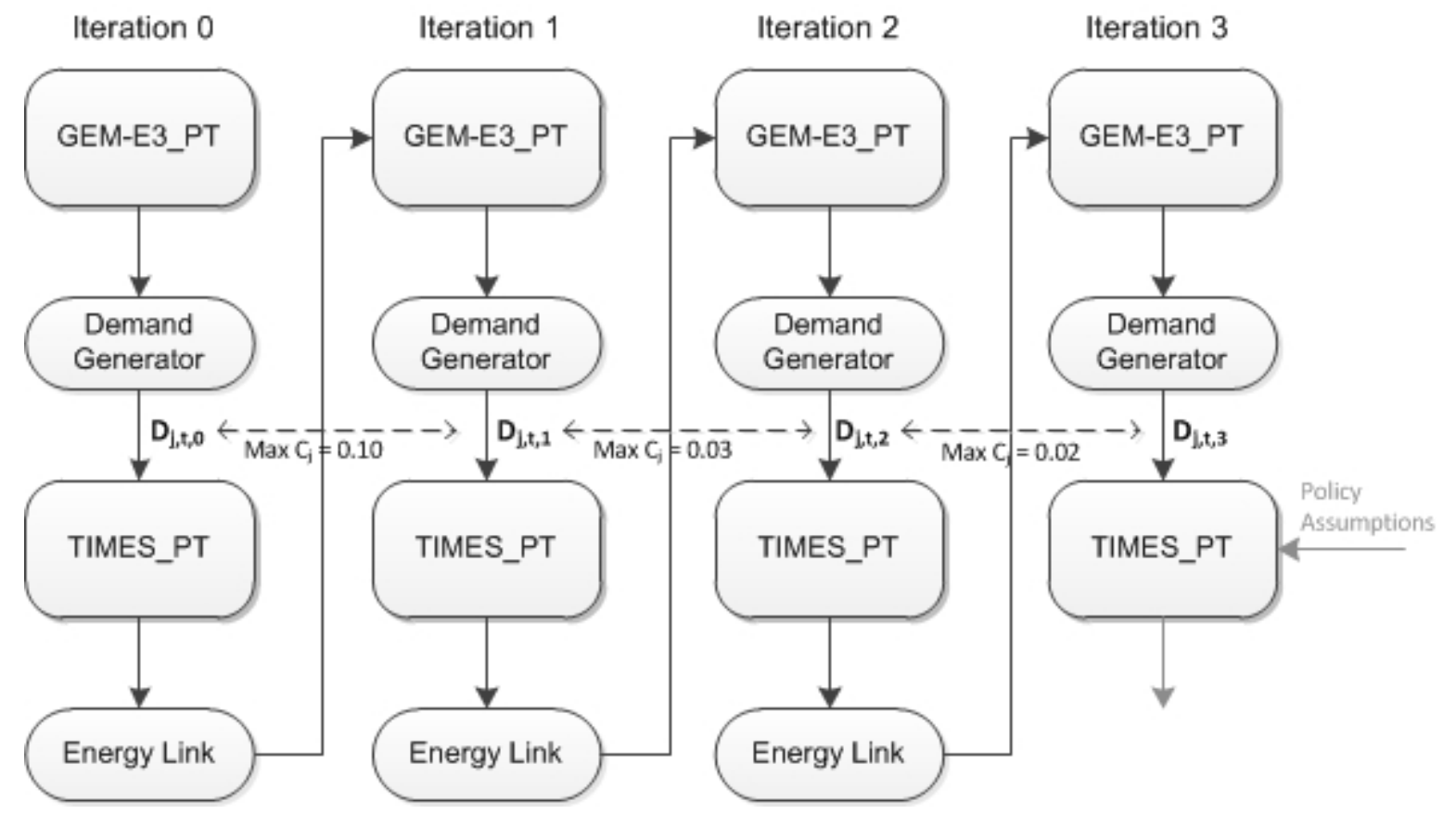

Figure 4 - Schematic view of HYBTEP iteration process for the CALIB scenario (grey lines in iteration 3 represent the initial step of the policy scenarios).

Table 2 indicates that in general, without a soft-link, energy services demand may be underestimated, especially for residential and passengers' mobility and for energy intensive sectors such cement, paper and ceramic in the long term. The differences between energy services demand before and after the calibration are related to the 
consumption and effective cost of energy in each sector and its impact on the macroeconomic drivers. The technological choices of TIMES_PT minimize energy system costs, inducing generally a reduction in energy costs (exception for iron and steel and other industry), which were assumed for GEM-E3_PT with positive impacts on the demand for energy services.

Table 2 - Demand for energy services, materials and mobility in selected sectors, in iteration 0 and 3 of CALIB scenario for 2030 and 2050

\begin{tabular}{l|rrc|rrr}
\hline & \multicolumn{3}{|c|}{$\mathbf{2 0 3 0}$} & \multicolumn{3}{c}{$\mathbf{2 0 5 0}$} \\
\hline \multicolumn{1}{c|}{ Demand } & \multicolumn{1}{c|}{ It. 0 } & \multicolumn{1}{c|}{ It.3 } & Difference (\%) & \multicolumn{1}{c}{ It.0 } & \multicolumn{1}{c}{ It.3 } & Difference (\%) \\
\hline Residential (PJ) & 104.5 & 110.3 & $6 \%$ & 122.7 & 130.3 & $6 \%$ \\
Services (PJ) & 172.6 & 177.8 & $3 \%$ & 196.8 & 203.6 & $3 \%$ \\
Passenger.km & 94894.8 & 100259.4 & $6 \%$ & 113404.7 & 120675.1 & $6 \%$ \\
Tonne.km & 32857.9 & 33506.9 & $2 \%$ & 41626.8 & 42784.4 & $3 \%$ \\
Chemical industry (PJ) & 24.4 & 24.9 & $2 \%$ & 30.8 & 30.6 & $-1 \%$ \\
Iron and Steel (Mt) & 2.0 & 2.0 & $-4 \%$ & 2.5 & 2.4 & $-3 \%$ \\
Cement (Mt) & 10.2 & 10.3 & $1 \%$ & 11.6 & 12.1 & $5 \%$ \\
Paper (Mt) & 2.7 & 2.7 & $1 \%$ & 3.3 & 3.5 & $8 \%$ \\
Ceramic (Mt) & 29.7 & 30.1 & $1 \%$ & 37.3 & 40.6 & $9 \%$ \\
Other industries (PJ) & 85.1 & 84.2 & $-1 \%$ & 103.9 & 103.1 & $-1 \%$ \\
\hline
\end{tabular}

\subsection{Energy-climate policy scenarios}

In this section, we describe the key elements of the three policy scenarios aiming to decarbonize the energy system.

Current Policy Regulation (CPR): The current Portuguese energy-climate policy within the EU climate-energy package extended beyond 2020. This includes a reduction in GHG emissions, an increase in renewable energy consumption and an improvement in energy efficiency. 
i. Extension up to 2050 of the EU Effort Sharing Decision, i.e., Portugal can increase (from 2005 values) the emissions from sectors not included in the EU Emissions Trading System (EU-ETS) by $1 \%$.

ii. Decline of the EU-ETS emissions ceiling after 2020 at a linear rate of $1.5 \%$ p.a., i.e., lower than the current rate of decline, as defined in the Reference Scenario of EU Energy Roadmap [37]. The goal of the ETS scheme is to reduce EU ETS emissions, with national allocations units based on benchmarks. For simplicity and due to the absence of national information beyond 2020, we assumed that the EU wide ETS annual emission ceiling also applies to Portugal. No trade in emissions permits, exogenous $\mathrm{CO}_{2}$ price or other policy instrument was assumed for ETS emissions besides the cap.

iii. The national renewable targets stated by National Renewable Energy Action Plan (NREAP) [38] are maintained through 2050: $31 \%$ of renewable energy sources (RES) consumption in final energy demand; $49.6 \%$ of renewable electricity (RESE); $11.1 \%$ of RES in transport energy consumption (RES-T); and $33.6 \%$ of RES consumption on Heating and Cooling (RES-H).

iv. Extension up to 2050 of the national primary energy savings target defined by the National Energy Efficiency Action Plan (NEEAP) for 2020: 26\% [38]. CPR scenario does not include directly the measures presented in NEEAP, meaning that the deployment of efficient equipment is determined by TIMES_PT, based on costs. However, NEEAP primary energy consumption limit (925.3 PJ) was considered as an upper bound, ensuring compliance with the national goal.

v. No new 'conventional' coal power plants could be installed after 2015 following the EU Parliament's Environment Committee vote to limit the $\mathrm{CO}_{2}$ emissions for 
new large combustion plants (capacity over $0.3 \mathrm{GW}$ ) to a maximum of $500 \mathrm{~g}$ $\mathrm{CO}_{2} / \mathrm{kwh}(138.9 \mathrm{kt} / \mathrm{PJ})$.

$\mathrm{CO}_{2}$ price scenario (TAX): It comprises, in addition to the CPR assumptions, a domestic carbon tax on GHG emissions from energy consumption (Table 3) instead of the ETS and Non-ETS emissions caps. The $\mathrm{CO}_{2}$ tax is set at the highest carbon price scenario indicated in the EU roadmap for moving to a competitive low carbon economy [39] and is applied after 2020 uniformly to all sectors of the economy. In HYBTEP (through GEM-E3_PT), tax revenue was used to reduce endogenously the social security contributions of employees.

Table 3 - CO2 price $\left(\left(€_{08} / \mathrm{t} \mathrm{CO} 2 \mathrm{e}\right)[39]\right)$ considered in TAX policy scenario

\begin{tabular}{c|ccccccc}
\hline & $\mathbf{2 0 2 0}$ & $\mathbf{2 0 2 5}$ & $\mathbf{2 0 3 0}$ & $\mathbf{2 0 3 5}$ & $\mathbf{2 0 4 0}$ & $\mathbf{2 0 4 5}$ & $\mathbf{2 0 5 0}$ \\
\hline CO2 price $\left(\boldsymbol{\epsilon}_{08} / \mathrm{t} \mathrm{CO2e}\right)$ & 25 & 39 & 62 & 69 & 100 & 218 & 370 \\
\hline
\end{tabular}

RES support scenario (RES): It involves, in addition to the CPR assumptions, a monetary incentive to renewable energy, including renewable electricity, biofuels, and solar and biomass consumption in buildings and industries. The incentive goes from 50 $€_{08} / \mathrm{MWh}$ in 2020 to $191 €_{08} / \mathrm{MWh}$ in 2050 (half of the RES-value of High RES scenario of EU Energy Roadmap [37]). In HYBTEP, this feed-in tariff was modeled as a subsidy paid by the Government to the respective sector according to their renewable energy consumption. 
In addition to the HYBTEP runs, the policy scenarios were run by the standard TIMES_PT (without energy service-energy service-price elasticities) and by TIMES_ED (with elasticities). Following previous TIMES studies for Portugal $[33,40]$, the price elasticity was set at -0.3 , for all categories except, commercial cooking and public lighting, whose values were -0.2 , and residential cooking with -0.1 . Due to uncertainty in the estimated price elasticities, a sensitivity analysis considering higher (-0.5) and lower (-0.1) values was conducted as in [41]. The TIMES_PT endogenous energy prices defined in the CALIB scenario (last iteration), were taken as the base prices for TIMES_ED policy simulations.

\section{Results and Discussion}

This section discusses the impacts of the policy scenarios on the energy system, GHG emissions and the economy, by comparing the results from the HYBTEP with those from TIMES_ED and the standard TIMES_PT. This comparison allows us to evaluate the value added of incorporating the interactions among technological choices and the economic drivers. Results are present from 2030 onwards due to their small differences trough 2020 (inclusive), e.g., maximum difference in final energy consumption between the modelling tools (HYBTEP, TIMES_PT, TIMES_ED(-0.1), TIMES_ED(-0.3), TIMES_ED(-0.5)), in 2020, in each scenario, is less than $1.1 \%$.

\subsection{Impact on Energy Consumption}

Under CALIB scenario, and after the decline of energy demand due to the short term economic crises, final energy consumption presents a smooth increase of approximately 0.7\% p.a. between 2030 and 2050 (Figure 5), achieving in the latter year, values close 
to 2010 level. The final demand for energy differs across the modeling platforms for the policy scenarios considered. The extent of this variation varies across the scenarios modeled, as illustrated in Figure 5, and is mostly due to the mechanisms that each modeling tool is designed to examine. Under CRP policy scenario, HYBTEP and TIMES_ED(-0.3) assume also an annual growth in energy consumption of approximately $0.7 \%$. The maximum difference (1.4\%) between HYBTEP and TIMES_ED(-0.3) energy consumption suggests that the approaches are consistent. In fact, comparisons between HYBTEP and TIMES_PT, without elastic demand, and TIMES_ED(-0.5), with relatively elastic demand, shows differences below $2.0 \%$. These outcomes underscore the fact that, when compared with calibration scenario (CALIB), CPR does not induce major changes in the energy system structure and costs and on the economy, and thus all the modelling tools present close outcomes.

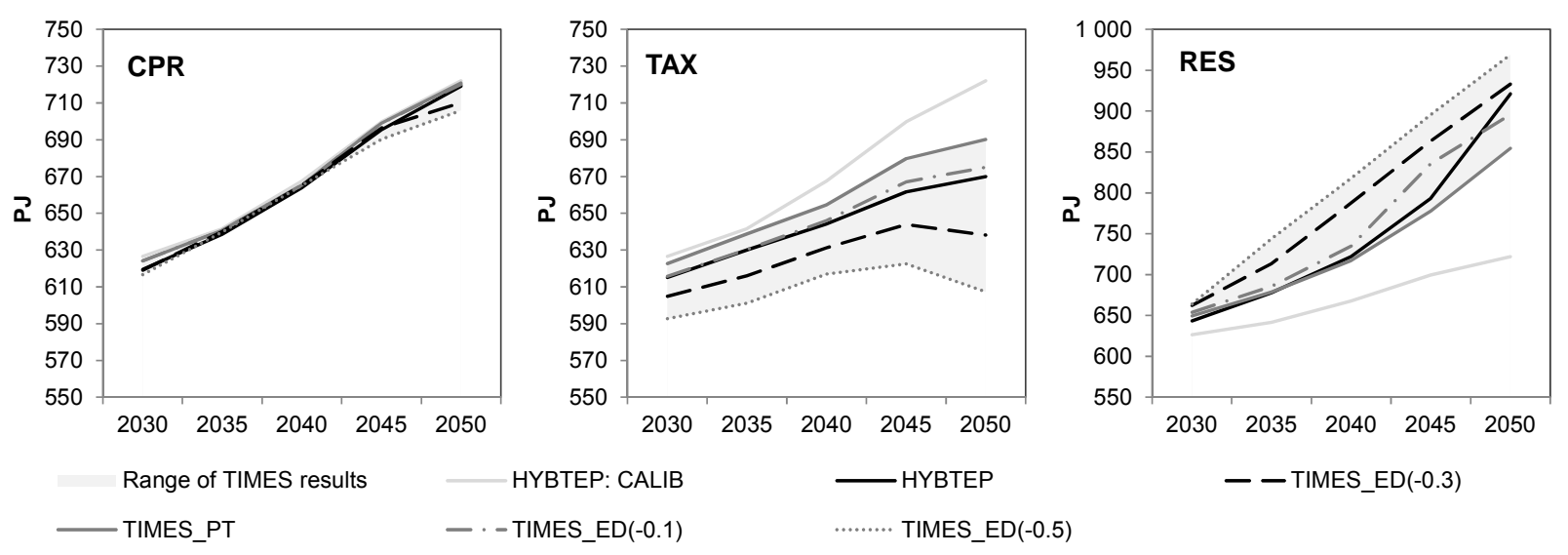

Figure 5 - Final energy consumption pathway per scenario and modelling tool (results from CALIB scenario are represented in each chart by HYBTEP:CALIB)

Under the TAX and RES policy scenarios, however, important differences arise. The introduction of a $\mathrm{CO}_{2}$ tax represents an additional expense, both directly and indirectly, through the increase in costs from a shift to alternative energy carriers and the 
deployment of more expensive technologies. The increase in energy costs results, in both HYBTEP and TIMES_ED(-0.3), in a decrease of energy consumption, when compared with a non-elastic run (TIMES_PT outcomes), which in its turn, shows a lower energy consumption than CALIB scenario due to the presence of more efficient equipment (e.g. heat pumps in buildings). HYBTEP and TIMES_ED(-0.3) present a maximum difference of $5.0 \%$ in total final energy consumption, with the hybrid tool depicting the larger demand over the modeling horizon. In HYBTEP, the carbon price induces an increase in production costs, leading to a decrease in quantity. However, the $\mathrm{CO}_{2}$ tax also represents a source of additional revenue to government. The income is recycled to the economy through a reduction in labor costs, which can partially offset the increase in energy costs in production. This economic framework justifies the fact that HYBTEP shows a lower impact on energy consumption than TIMES_ED(-0.3).

The differences across modeling tools, with respect to total final energy consumption, differ across energy carriers due to dissimilarities among economic sectors. Under the TAX scenario, the largest divergence between the HYBTEP and TIMES_ED(-0.3) results is associated with fossil energy demand, especial after 2040, with the hybrid platform defining consumption levels 12.9\% above the BU model in 2050 (Figure 6). This is mostly associated with transports and other industry, for which HYBTEP defines greater levels of energy consumption, namely for oil products in transportation $(+20.3 \%$ in 2050) and natural gas (+13.7\% in 2050) in other industry. 

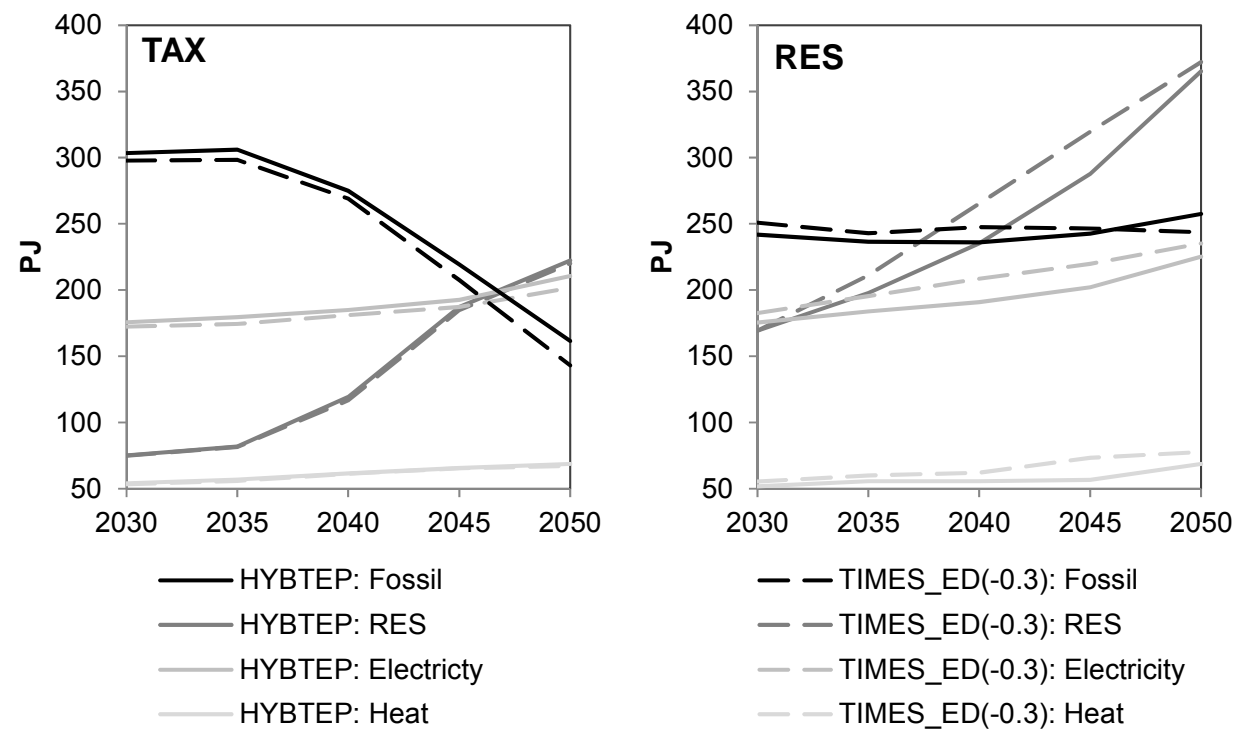

Figure 6 - Final energy consumption pathway per energy carrier under TAX and RES scenarios, modeled by HYBTEP and TIMES_ED(-0.3)

In contrast to a CO2 tax, in HYBTEP, additional RES financial support from the government means less available revenues to spend on public consumption and investment and to reduce employers' social security tax (i.e., to reduce labor costs). The fiscal dimensions of the subsidy are not considered by TIMES_ED(-0.3), in which the subsidy represents a simple reduction in energy price with positive effects in energy consumption as illustrated in Figure 5. For this reason, although both models assume an increase in total final energy consumption above $1.7 \%$ p.a. between 2030 and 2050 in RES scenario, the BU model presents greater values (up to $8.3 \%$ ) over the modeling horizon. In fact, up to 2040, HYBTEP results are very close to the inelastic TIMES_PT, suggesting that the reduction in energy prices, financed by an increase in labor costs, leads in general to a relatively small impact on production and on the demand for energy services.

As shown in Figure 6, for the RES scenario, the most substantial differences between the models in terms of energy carriers are related to renewable, through 2045 , and to 
power and heat energy consumption, with TIMES_ED(-0.3) presenting consumption levels greater than HYBTEP. The higher renewable energy consumption is related with biomass consumption in industry (e.g., $+13.5 \%$ of biomass consumption in 2040 and 2045), while for electricity demand, the higher values are due to greater levels of consumption for residential consumers, services, and other industry sectors (e.g., +9.7 in 2040).

The economic framework of HYBTEP explained above, justifies the fact that for most sectors, HYBTEP presents higher values of energy consumption than TIMES_ED(-0.3) under TAX scenario and lower for RES scenario (Figure 7), leading to a similar relation in terms of energy carriers. The exception is the demand for oil products in 2050 , under RES scenario due to transports behavior.

The sensitivity analysis with respect to the energy service-price elasticities highlights the impact of this parameter on energy consumption, as the BU model outcomes can present differences (TIMES_PT vis-à-vis TIMES_ED(-0.5)) from $5.1 \%$ to $13.6 \%$ and from $-2.2 \%$ to $-11.8 \%$ in the total final energy consumption in the TAX and RES scenario, respectively, for the period 2030 to 2050 (Figure 5). The elasticities implicit in the TIMES_ED stem from own price and cross price effects that are representative of the cost-effectiveness of energy technologies. This means that the elasticities will implicitly vary across scenarios and years. Under the TAX scenario, HYBTEP total final energy consumption is close to TIMES_ED(-0.1) values, while under the RES scenario the hybrid model show a lower degree of responsiveness to price changes, closer to the TIMES_PT results, with exception of the year 2050. This general outcome is associated with end-use sectors behavior, which varies significantly depending on the elasticity considered (Figure 7). For energy intensive and other industry, for example, the results 
from TIMES_PT and TIMES_ED(-0.5) can vary by more than $20 \%$ under RES scenario. This demonstrates the high degree of uncertainty associated with the use of energy service-price elasticities and its impact on sectors energy consumption. Since TIMES elasticities are mostly homogenous across sectors, the model does not capture its specificities. Thus, in general, the greater the energy services elasticity, the lower is energy consumption under the TAX scenario and the higher it is for the RES scenario, although some technology choices may alter this relationship, as is the case for transportation, which lead to an inflexion in the relation between oil products consumption from TIMES_ED(-0.3) and HYBTEP in 2050. 

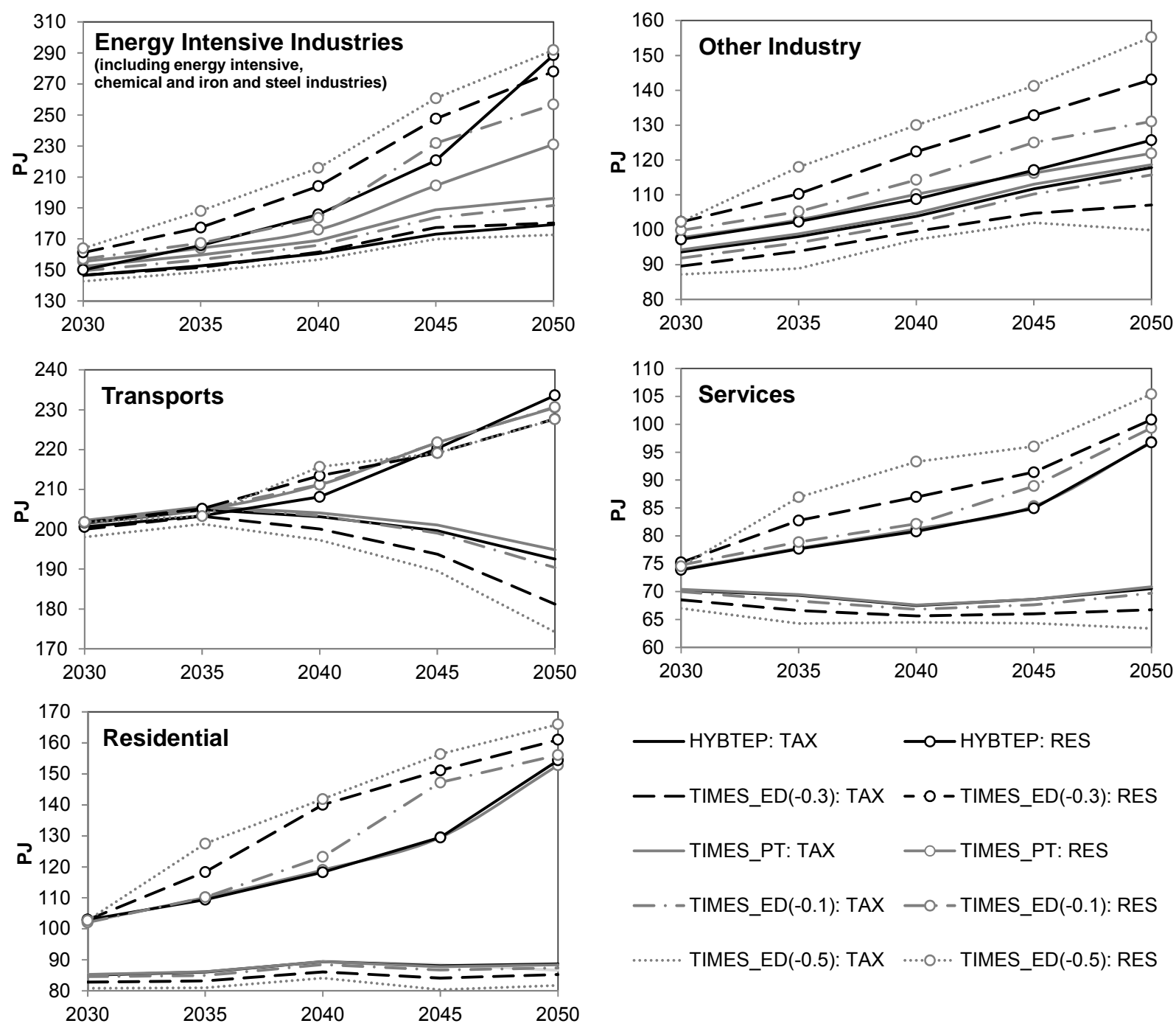

Figure 7 - Final energy consumption pathway per sector and modelling tool under TAX and RES scenarios

There is no linear relation between HYBTEP results and TIMES elasticities, as price responsiveness varies across sectors and scenarios. In general, HYBTEP depicts less elastic behavior than TIMES_ED(-0.3), being almost inelastic in some sectors, such as residential, services and other industry for both TAX and RES policy scenarios. For energy intensive industries and transports sectors, under TAX scenario, the hybrid platform results are more close to TIMES_ED(-0.3) and TIMES_ED(-0.1), respectively. 
While, in RES scenario, in the long term, HYBTEP shows higher levels of energy consumption for these two sectors, illustrating a greater degree of responsiveness, near the end of the modeling period with large subsidy to RES.

Besides the impact of the revenues recycling scheme explained above, in HYBTEP, the sectors are connected through intermediate consumption, and thus, variations in the production price of one sector, also affect domestic demand and other sectors production. In TIMES, with exception of the energy sector (e.g. power or refinery), theses linkages are completed ignored, justifying the different behavior of the two modelling tools.

\subsection{Impact on GHG emissions}

The changes to energy consumption described above yield congruent effects in GHG emissions as depicted in Figure 8. Under the cost-effective CALIB scenario, GHG emissions increase at $0.5 \%$ p.a., reaching, in $2050,2 \%$ above 1990 values. For the CPR scenario, both HYBTEP and TIMES define a smooth evolution in GHG emissions, achieving in $2050,-11 \%$ to $-12 \%$ of the 1990 emissions, including the outcomes from TIMES_PT and TIMES_ED(-0.5). This reduction of GHG emissions comparing to CALIB scenario is due to the decline of the EU-ETS emissions ceiling and is mostly associated with power production, as RES-E increases in 2050 from $68 \%$ under CALIB scenario to $78 \%$ under CPR for all the modeling tools. 


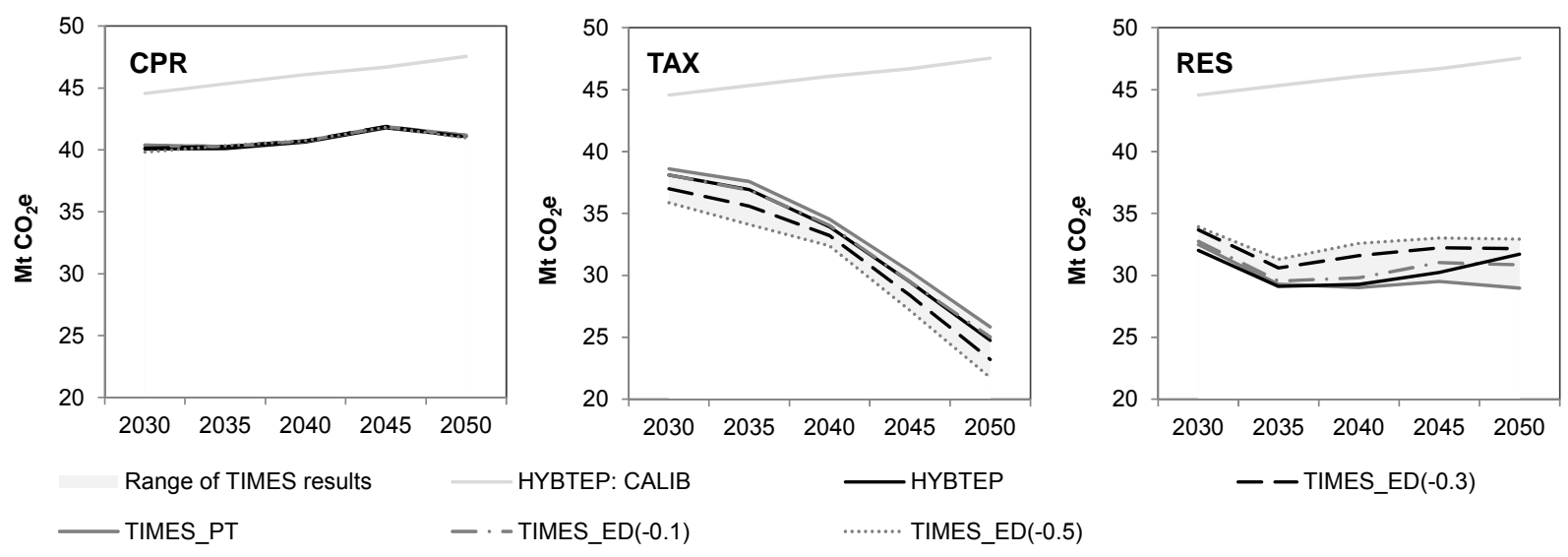

Figure 8 - Total GHG emissions pathway per scenario and modelling tool

Under the TAX scenario, GHG emissions reduction follows the shift from fossil to renewable energy, with HYBTEP showing, over the entire modeling horizon, higher emissions than TIMES_ED(-0.3). By 2050, the hybrid tool suggests a decrease of $47 \%$ in GHG emissions (from 1990 level), while the BU model suggests a $50 \%$ reduction, both insufficient to meet the $80 \%$ reduction defined by the EU objective. Power production and transports are the principal sectors responsible for this reduction. In 2050, RES-E, mostly supported by hydro, onshore wind and solar PV, represent $88 \%$ of the total electricity generated for both HYBTEP and TIMES_ED(-0.3), while RES-T (associated with biofuels and electric vehicles) achieves $61 \%$ and $65 \%$ of the energy demand in transports for HYBTEP and TIMES_ED(-0.3), respectively.

For the RES scenario, the models display a sharp decrease in GHG emissions from 2030 to 2035, due to the decline in natural gas consumption in power and heat production, increasing thereafter. Although the differences between HYBTEP and TIMES_ED(-0.3) emissions are always greater than $5 \%$, by 2050 , the two models produce similar reductions in GHG emissions, around $-31 \% /-32 \%$ relative to 1990 levels. Again, this reduction in GHG emissions is mostly due an increase in renewable energy 
in power sector, with renewable energy sources accounting for $97 \%$ of electricity generation in 2050 for all the modeling tools. Besides the renewable technologies mentioned for TAX scenario, in RES, this requires the deployment of offshore wind, wave and concentrated solar power.

The sensitivity analysis of TIMES energy services-price elasticities illustrates that under the TAX scenario, larger elasticities produce larger reductions in GHG emissions, while the opposite occurs for the RES scenario. In the TAX scenario, total emissions in the TIMES model (i.e. TIMES_PT versus TIMES_ED(-0.5)) differ by more than $6 \%$ across the entire modeling horizon achieving a maximum difference of $16 \%$ in 2050 . In this year, and compare to 1990 values, the BU model defines an emissions reduction of $44 \%$ and 53\%, according to TIMES_PT and TIMES_ED(-0.5), respectively. Besides demand reduction, transports play an important role in carbon mitigation differences as renewable energy represent $61 \%$ and $68 \%$ of transportation consumption for the TIMES_PT and TIMES_ED(-0.5), respectively.

For the RES scenario, TIMES_ED(-0.5) sets GHG emissions $12 \%$ above those of TIMES_PT outcomes after 2040. In 2050, this corresponds to a reduction relative to 1990 levels of $38 \%$ by TIMES_PT to $29 \%$ according to TIMES_ED(-0.5). These differences are mostly related to demand fluctuations, as no significant differences in terms of renewable energy are observed.

As with total final energy consumption, emissions in the TAX scenario under the HYBTEP modeling platform are very close to those derived from TIMES_ED(-0.1), while for RES, the hybrid tool exhibits GHG emissions close to the inelastic TIMES_PT, rising 
after 2040, in the direction of TIMES_ED(-0.3) values due to demand behavior and technological choices in energy intensive industries and transportation (see Figure 7).

\subsection{Economic Impacts}

A substantial added value of HYBTEP, relative to the TIMES model, is the ability to compute the economic impacts of the scenarios modeled. Table 4 illustrates the economic impacts of the three policy scenarios, reported as a percent change from the CALIB scenario.

Table 4 - Economic impacts for 2030 and 2050 modelled by HYBTEP. CALIB values in index (2005=1), remainder scenarios as percentage change from CALIB results

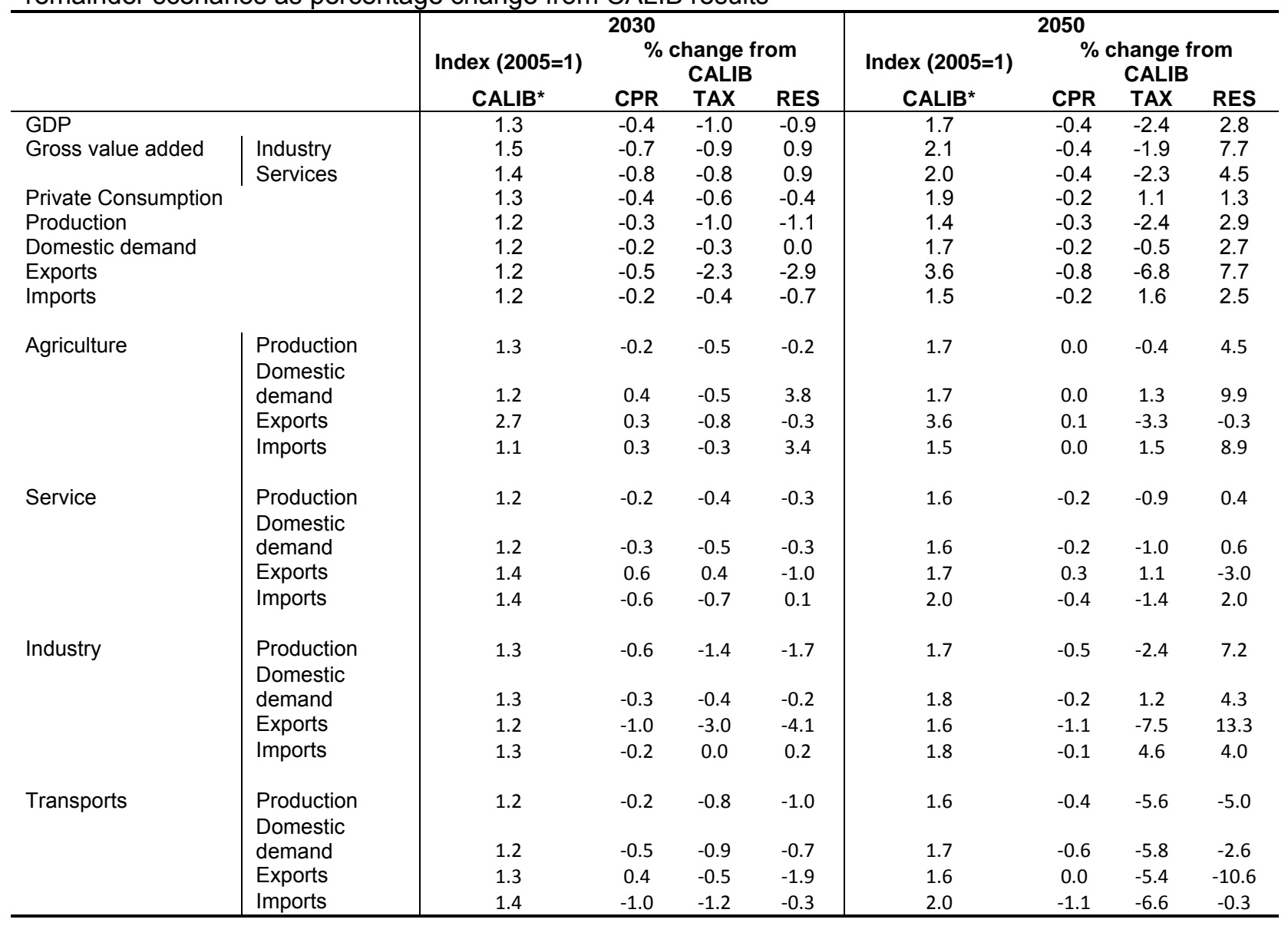

*The economic drivers of CALIB scenario are the resultant from iteration 3, described on section 3.1., which originated TIMES_PT demand. 
Over the medium term (2030), GDP falls by $0.4 \%, 1.0 \%$ and $0.9 \%$, for CPR, TAX and RES scenarios, respectively. Over the long term (2050), and due to the moderate CPR assumptions, GDP losses remain at $0.4 \%$, while the increase in energy costs in the TAX scenario, induces a decrease of $2.4 \%$ in GDP. Unlike CPR and TAX scenarios, RES produces an increase in gross value added (GVA), especially for industry $(7.7 \%)$ and GDP gains of $2.8 \%$.

The mechanisms underlying these results are due to the balance between the financial instrument modeled and the revenue recycling scheme assumed, translated roughly in a balance between energy and labor costs. The introduction of a $\mathrm{CO}_{2}$ tax increases production costs, leading to higher purchase prices with subsequent reductions to private demand, as observed for the medium term. Nevertheless, because tax revenues are used to reduce employers' social security contributions (reductions of $4.9 \%$ in 2050 comparing with CALIB) and thus labor costs, the negative effect of the carbon price on production is offset in 2050 , leading to an increase of private consumption (1.1\%). The decline in exports by $6.8 \%$, leads to a reduction of production in $2.4 \%$, and thus, the increase of private consumption is satisfied by an increase in imports (1.6\%).

Government support for renewable energy (RES scenario) contributes, on one hand, to a reduction in production costs as a result of lower energy costs. On the other hand, the increase in the social security tax rate by $8.5 \%$ in 2050 , needed to finance the renewable energy subsidy, leads to an increase in production costs. The net effect is a negative impact in both GDP and private consumption in the medium term, but a positive effect in 2050 . The results indicate that in the long term the RES support will induce an increase in domestic production (2.7\%) and exports $(7.7 \%)$. 
HYTEP allows for the study of the mechanism behind the sector impacts of policies. Under a TAX scenario, over the long term, domestic demand for transportation and services drives the reduction in output. Although, domestic demand in both industry and agriculture increase, the decrease in exports offsets the possible rise of the sectors production. Under RES in 2050, almost all the sectors see an increase in production, with the exception of transports, for which the energy structure is more costly than CALIB even with a RES subsidy ${ }^{6}$. For industry, the production increase is mainly a result of exports growth (13\%), while for services and agriculture is the domestic demand that gives rise to the increase in output.

The impact of the policy scenarios on the economy can also influence energy system indicators which are commonly used by policy makers to assess, for example, energy efficiency in each sector of economic activity. In some cases, the behavior of the HYBTEP platform versus TIMES in terms of energy consumption is not reflected in energy intensity (Figure), due to differences in economic development. Under TAX scenario, for example, HYBTEP defines an energy consumption for transports above TIMES_ED(-0.3) values, i.e., between TIMES_ED(-0.1) and TIMES_PT outcomes. However, the reduction of GDP computed by HYBTEP makes the sector's energy intensity higher than the ones resulting from the BU model, which assumes no changes in the macroeconomic drivers. In RES scenario, the energy consumption in services computed by HYBTEP is similar to the inelastic TIMES_PT. Yet, due to the increase in

\footnotetext{
${ }^{6}$ It should be underline that TIMES optimizes the energy system as a whole, this means that even in the presence of a subsidy, and although globally the total energy system costs are lower, some sectors can experience higher costs due to different technology choices in others, which can originate cheap resources depletion. In the case of transports this is associated with the increase of biomass price, which is used to produce second generation of liquid biofuels.
} 
GVA of services reported by HYBTEP, the hybrid tool defines an energy intensity lower than the one calculated trough TIMES results.

TAX
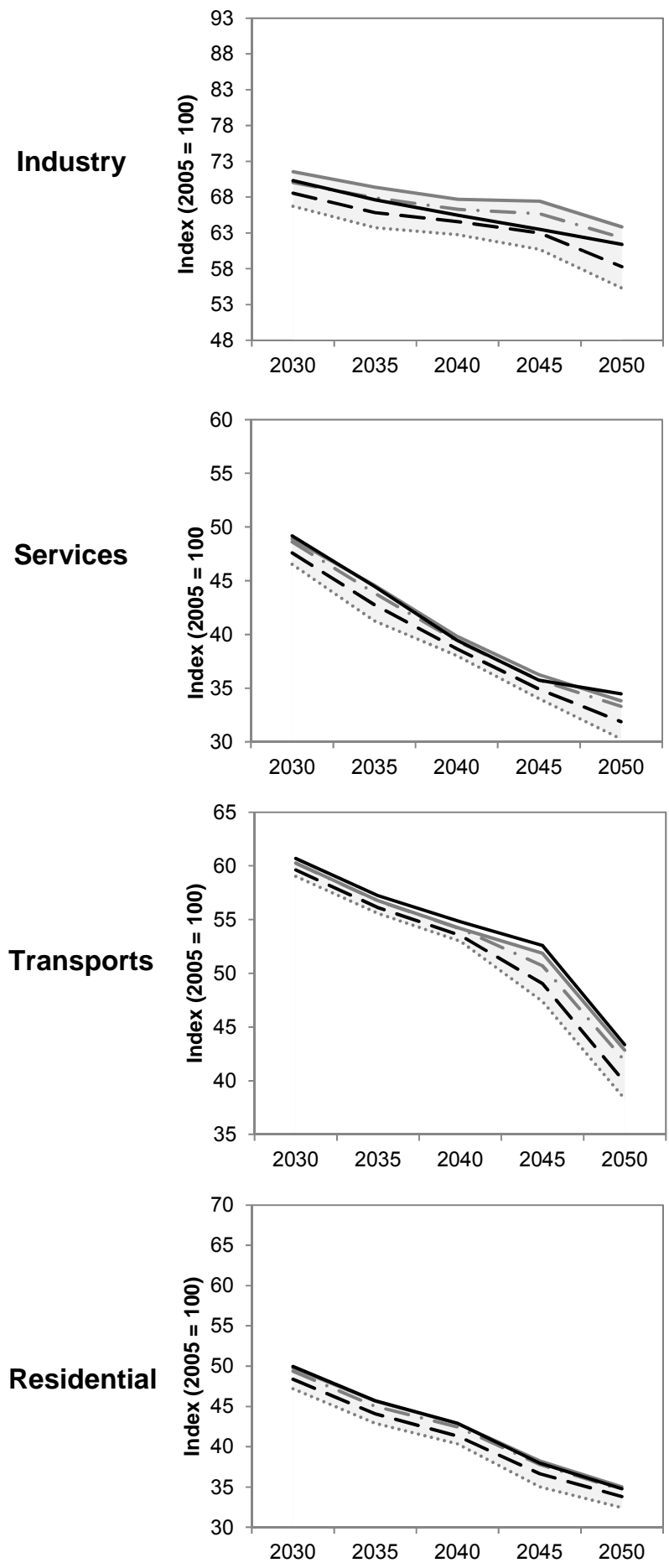

RES
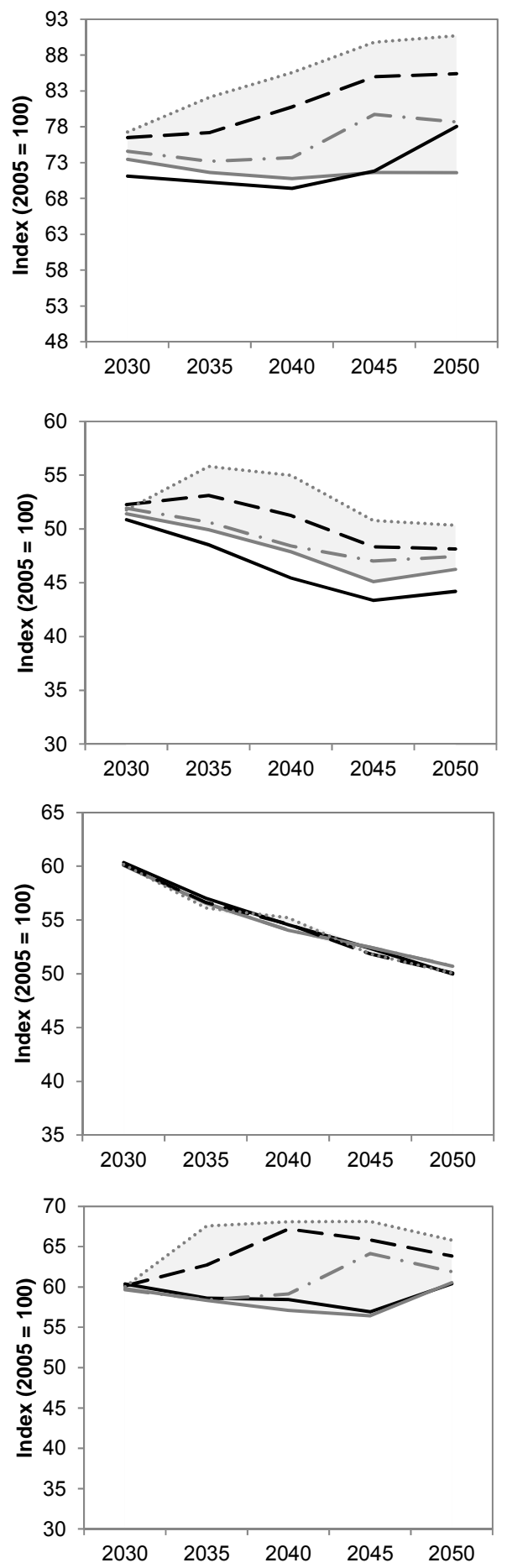

Figure 9 - Sector energy intensity pathway per modelling tool under TAX and RES scenarios, measured as: Industry (energy consumption/GVA), services: (energy consumption/GVA) Transports (energy consumption/GDP), residential (energy consumption/private consumption). 
The most significant difference between HYBTEP and TIMES sector's energy intensity pathway is associated with industry. For the hybrid platform, under TAX scenario, industry energy intensity follows a linear decrease path; whereas, TIMES defines a more pronounced decline after 2045. Under RES scenario and according to TIMES, in the long term industry's energy intensity stabilizes or experiences a smooth decrease, while HYBTEP sets after 2040, an increases of the sector energy intensity. These differences are mostly justified by the divergences on the sector production/energy service demand, which in its turn induce changes in the energy choices.

The sensitivity analysis with respect to TIMES energy service-price elasticities shows uncertainty in the energy intensity of some sectors. For instance, in the residential sector under the RES scenario, TIMES_ED(-0.5) sets an increase in energy intensity through 2035 declining thereafter. For TIMES_ED(-0.3), this decline occurs only after 2040 and for TIMES_ED(-0.1) after 2045. The energy intensity specified by TIMES_PT falls from 2030 through 2045, rising thereafter, describing a path equal to HYBTEP. The RES scenario similarly produces varied industry energy intensities. TIMES_ED(-0.5) and TIMES_ED(-0.3) exhibits an increase of energy intensity in the beginning of the time horizon, while for TIMES_ED(-0.1) and TIMES_PT this occurs only after 2040.

\section{Concluding Remarks}

Traditionally, CGE and BU models have not allowed for an integrated assessment of climate and energy policy instruments with detailed technology profile for the energy sector and its macroeconomic effects, both of which are essential metrics for policy makers. This paper describes a method of soft-linking 'full-form', multi-sector BU and CGE models, resulting in an integrated modeling platform - HYBTEP. Since the main 
structure of each model is maintained, HYBTEP accommodates an extensive group of technologies and economic responses, allowing for the analysis of the economic, technological and environmental impact of energy and climate policies.

In HYBTEP, energy prices and consumption are included in a comprehensive economic context, and accordingly changes in the energy sector affect factor demand, intermediate demand, output and private consumption, as well as the trade balance and government revenues. This economic framework allows us to examine the mechanisms driving changes in demand, namely those associated with the changes in domestic production, making the analysis more transparent. The detail of HYBTEP allows us to evaluate the impact of energy and climate policy on specific sectors, instead of aggregate macroeconomic variables, as is usually analyzed with hybrid macroeconomic models.

To assess the advantages of HYBTEP relative to the traditional BU approach (including the response to prices change through energy service price-elasticities), we compared the outcomes of three policy scenarios representing the current Portuguese energy and climate policy and additional policy instruments for GHG mitigation and an increase in renewable energy.

The application for Portugal indicates some important differences between the modelling tools, mostly related to the impact of the policy scenarios on energy system costs and thus on demand for energy services, which in turn affects energy consumption and GHG emissions. As the deployment of technologies may differ across policy scenarios, sectors and years, the implied price and energy system structures are not constant. As a result, it is not possible to specify a general relationship between HYTBEP and TIMES 
energy service-price elasticities. TIMES energy demand reductions are only affected by its elasticities and endogenously determined effective energy prices. Energy consumption and GHG emissions can change substantially according to the energy service elasticity considered. The uncertainty surrounding the elasticity parameters, due to the lack of national studies, can thus lead to uncertainty in the model results.

Naturally, the HYBTEP results presented here have some limitations, mainly inherited from each of the two models being linked. The hybrid platform assumes perfect competitive markets, except labor and considers the optimism of TIMES model over future technologies and its deployment, which can result in a lower bound of the macroeconomic impacts of energy and climate policy scenarios. Despite these limitations, and this is the main point of this paper, our results illustrate that the HYBTEP platform has advantages compared to independent use of conventional BU and TD models, in the development and analysis of energy and climate policy scenarios. These advantages stem from the integration of the strengths of a detailed technology model, namely the identification of mitigation technologies, with those from an economic tool, namely the impact of these policies on macroeconomic drivers. A major conclusion concerns the increase of transparency of modeling outcomes achieved with the HYBTEP platform, since the economic framework allows us to understand the mechanisms driving the evolution of energy demand while taking into account the costeffective energy profile from a technological model, which results in a higher confidence for decision making. 


\section{Acknowledgements}

This work was made possible by the financial support of the Portuguese Science and

Technology Foundation (FCT) through the funding of the $\mathrm{HybCO}_{2}$ research project (PTDC/AAC-CLI/105164/2008) and the doctoral work of Patrícia Fortes (SFRH/BD/27549/2006).

\section{References}

[1] Böhringer C, Rutherford TF. Combining bottom-up and top-down. Energy Economics 2008;30:574-96.

[2] Bataille C, Jaccard M, Nyboer J, Rivers N. Towards General Equilibrium iu a TechnologyRich Model with Empirically Estimated Behavioral Parameters. Energy Journal 2006;27:93-112.

[3] Bataille CGF, Columbia B. Design and Application of a Energy-Economy Policy Model with Micro and Macro Economic Dynamics. Simon Fraser University, Vancouver, 2005.

[4] Labriet M, Kanudia A, Loulou R. Climate mitigation under an uncertain technology future : A TIAM-World analysis. Energy Economics 2012;34:S366-S377.

[5] Duerinck J, Van Regemorter D. Residential energy demand elasticities : what lessons can be learned from bottom-up and top-down. International Energy Workshop, 2011, p. 1-19.

[6] Grubb M, Kohler J, Anderson D. Induced Technical Change in Energy and Envionmental Modeling: Analytic Approaches and Policy Implications. Annual Review of Energy and the Environment 2002;27:271-308.

[7] Böhringer C, Rutherford TF. Integrated assessment of energy policies: Decomposing topdown and bottom-up. Journal of Economic Dynamics and Control 2009;33:1648-61.

[8] Hourcade J, Jaccard M, Bataille C, Ghersi F. Hybrid Modeling : New Answers to Old Challenges. The Energy Journal 2006;2:1-12.

[9] Hoffman KC, Jorgenson D. Economic and technological models for evaluation of energy policy. The Bell Journal of Economics 1976;8:444-66.

[10] Labriet M, Drouet L, Vielle M, Haurie A, Kanudia A, Loulou R. Coupled Bottom-Up and Top-Down Modelling to Investigate Cooperative Climate Policies. Les Cahiers du GERAD, Montreal: 2010, p. 1-17. 
[11] Martinsen T. Introducing technology learning for energy technologies in a national CGE model through soft links to global and national energy models. Energy Policy 2011;39:3327-36.

[12] Schäfer A, Jacoby HD. Technology detail in a multisector CGE model: transport under climate policy. Energy Economics 2005;27:1-24.

[13] Drouet L, Haurie A, Labriet M, Thalmann P, Vielle M, Viguier L. A coupled bottom-up/topdown model for GHG abatement scenarios in the Swiss housing sector. In: Loulu R, Waaub J-P, Zaccour G, editors. Energy and Environment, Montreal: Springer; 2005, p. 27-61.

[14] Manne A, Wene C-0. MARKAL-MACRO: A Linked Model for Energy-Economy Analysis. New York, USA: 1992.

[15] Manne A, Mendelsohn R, Richels R. MERGE: A model for evaluating regional and global effects of. Energy Policy 1995;23:17-34.

[16] Messner S, Schrattenholzer L. MESSAGE-MACRO: linking an energy supply model with a macroeconomic module and solving it iteratively. Energy 2000;25:267-82.

[17] Bosetti V, Carraro C, Galeotti M, Massetti E, Tavoni M. WITCH: A World Induced Technical Change Hybrid Model. The Energy Journal 2006:13-38.

[18] Strachan N, Kannan R. Hybrid modelling of long-term carbon reduction scenarios for the UK. Energy Economics 2008;30:2947-63.

[19] Bohringer C. The synthesis of bottom-up and top-down in energy policy modeling. Energy Economics 1998;20:233-48.

[20] Frei CW, Haldi P-A, Sarlos G. Dynamic formulation of a top-down and bottom-up merging energy policy model. Energy Policy 2003;31:1017-31.

[21] Sue Wing I. The synthesis of bottom-up and top-down approaches to climate policy modeling: Electric power technology detail in a social accounting framework. Energy Economics 2008;30:547-73.

[22] Proença S, St. Aubyn M. Hybrid modeling to support energy-climate policy: Effects of feed-in tariffs to promote renewable energy in Portugal. Energy Economics 2013;38:17685.

[23] Tuladhar SD, Yuan M, Bernstein P, Montgomery WD, Smith A. A top - down bottom - up modeling approach to climate change policy analysis. Energy Economics 2009;31:S223S234.

[24] Lanz B, Rausch S. General equilibrium, electricity generation technologies and the cost of carbon abatement: A structural sensitivity analysis. Energy Economics 2011;33:1035-47.

[25] Loulou R, Remme U, Kanudia A, Lehtila A, Goldstein G. Documentation for the TIMES model part I to III. Paris: 2005. 
[26] E3M - Lab. GEM-E3: Model Manual. Athens: 2010. E3M - Lab. GEM-E3: Model Manual. Athens: 2010. [Available at: http://147.102.23.135/e3mlab/GEM\%20\%20E3\%20Manual/Manual\%20of\%20GEM-E3.pdf

[27] INE (Portuguese National Statitics Office). National Accounts (Series 1995-2011). Lisbon: 2013. [Available at:

http://www.ine.pt/xportal/xmain?xpid=INE\&xpgid=ine_contas_nacionais\&perfil=10401221 $7 \&$ INST $=116633478 \&$ contexto=am]

[28] EC (European Commission). The European System of Accounts (ESA95): Supply Use and Input-Output tables (Series 2000-2009). Brussels: 2011. [Available at: http://epp.eurostat.ec.europa.eu/portal/page/portal/esa95_supply_use_input_tables/data/ workbooks]

[29] DGEG (Directorate-General of Energy and Geology). National Energy Balances (19902013). Lisbon: 2013. [Available at: http://www.dgeg.pt/]

[30] APA (Portuguese Environment Agency). Portuguese national inventory report on greenhouse gases (1990-2010). Lisbon: 2012.

[31] IEA (International Energy Agency). Energy Technology Perspectives 2012: Pathways to a Clean Energy System. Paris: OECD; 2012.

[32] IEA (International Energy Agency). End-use prices: Energy prices in national currency per unit. 2011.

[33] Simões S, Cleto J, Fortes P, Seixas J, Huppes G. Cost of energy and environmental policy in Portuguese CO2 abatement-scenario analysis to 2020. Energy Policy 2008;36:3598-611.

[34] Turton H. ECLIPSE: An integrated energy-economy model for climate policy and scenario analysis. Energy 2008;33:1754-69.

[35] Alvarenga A, Carvalho P, Lobo A, Rogado C, Azevedo F, Guerra MD, et al. Long-term Future of the Portuguese Economy: A Scenario Building Process. Department of Foresight and Planning and International Affairs. Lisbon: 2011.

[36] EC (European Commission). The 2012 Ageing Report: Economic and budgetary projections for the 27 EU Member States (2010-2060), European Economy 2|2012. Brussels: 2012.

[37] EC (European Commission). Communication from the Commission to the European Parliament, the Council, the European Economic and Social Committee and the Committee of the Regions. Energy Roadmap 2050. (COM(2011) 885 final) 2011.

[38] RCM 20/2013. Resolução do Conselho de Ministros n.o 20/2013 [Resolution of Council of Ministers 20/2013] 2013:2022-91.

[39] EC (European Commission). Communication from the Commission to the European Parliament, the Council, the European Economic and Social Committee and the 
Committee of the Regions. A roadmap for moving to a competitive low carbon economy in 2050 (COM(2011) 112 final) 2011.

[40] Fortes P, Simões S, Seixas J, Van Regemorter D, Ferreira F. Top-down and bottom-up modelling to support low-carbon scenarios: climate policy implications. Climate Policy 2013;13:285-304.

[41] Chen W, Wu Z, He J, Gao P, Xu S. Carbon emission control strategies for China: A comparative study with partial and general equilibrium versions of the China MARKAL model. Energy 2007;32:59-72. 